\title{
A GROWTH MODEL FOR THE QUADRUPLE HELIX
}

\author{
Oscar Afonso', Sara Monteiro ${ }^{2}$, Maria Thompson ${ }^{3}$ \\ ${ }^{1}$ Faculty of Economics, University of Porto, CEFUP, OBEGEF, NIFIP, \\ R. Roberto Frias, 4200-464 Porto, Portugal \\ ${ }^{2}$ Faculty of Law, Nice Sophia Antipolis University, CEMAFI, 06050 Nice Cedex, France \\ ${ }^{3}$ Department of Economics, University of Minho, NIPE, 4710-057 Braga, Portugal \\ E-mails: ${ }^{1}$ oafonso@fep.up.pt (corresponding author); ${ }^{3}$ mjthompson@eeg.uminho.pt
}

Received 11 April 2011; accepted 19 September 2011

\begin{abstract}
We develop a R\&D-based growth model with productive public expenditure in order to frame the Quadruple Helix $(\mathrm{QH})$ innovation concept, based on four helices: Academia \& Technological Infrastructures, Firms, Government and Civil Society. Our motivation stems from acknowledgment that the relationship between these four helices and their joint impact on growth is in need of a theoretical framework. We aim to emphasise the importance to economic growth of innovation systems structured on these four helices. The introduced model confirms theoretically the notion that increases in: (i) complementarities between distinct productive units, or (ii) in productive government expenditure, lead to higher growth.
\end{abstract}

Keywords: economic growth, quadruple helix, innovation systems, government expenditure.

Reference to this paper should be made as follows: Afonso, O.; Monteiro, S.; Thompson, M. 2012. A growth model for the quadruple helix, Journal of Business Economics and Management 13(5): 849-865.

JEL Classification: O10, O18, O31.

\section{Introduction}

Wishing to contribute to the growing literature on innovation economies, we develop a R\&D-based growth model with productive public expenditure in order to provide the Quadruple Helix $(\mathrm{QH})$ innovation concept with a theoretical framework.

Today's economies are experiencing the emergence of a new nature of innovation, which distinguishes itself from that in the industrial era (OECD 2009), in which innovation consisted of technological developments performed by experts and research institutions in an environment characterised by a "silence is golden" culture.

Nowadays, innovation consists of all activities that create value by providing new solutions to concrete problems. Innovation arises as a result of co-creation between firms, citizens, universities and government, in a context marked by the existence of partnerships, collaborative networks and symbiotic relationships. The $\mathrm{QH}$ model describes this new economic environment. 
The QH is a development of the Triple Helix (TH) innovation theory, according to which the establishment of creative links between three helices - Academia, Government and Industry - originates new knowledge, technology or products and services that are conveyed in fulfilment of society needs (e.g., Etzkowitz, Leydesdorff 2000; Etzkowitz, Klofsten 2005). Arguing that the TH is not sufficient for long-term innovative growth, and wishing to emphasise the importance of integrating the perspective of media-based and culture-based citizens, the $\mathrm{QH}$ adds a fourth helix to the innovation system - Civil Society (e.g., Lijemark 2004; Khan, Al-Ansari 2005). As Barroso (2010) also writes, modern economies' growth requires cooperation between all economic agents, including social partners and Civil Society. Eriksson et al. (2005) also argue that in user-oriented innovation, users (Civil Society) are co-producers of innovation, their role being as important as those of research institutions, government support organisations and companies.

According to the QH theory, a country's economic structure lies then on four helices Academia \& Technological Infrastructures, Firms, Government and Civil Society -, with economic growth being generated through continuous innovations.

Wishing to frame theoretically the equally important role of all the QH helices in economic growth, we develop a model that connects the four pillars and investigate analytically their interactions and joint impact on growth.

Assuming a one-sector-structure, our proposed QH model captures the notion that the whole society is involved in innovation, which occurs as a result of co-creation between the four helices, connected through networks, partnerships and symbiotic relationships. Innovations are materialised by specialised productive units - Academia \& Technological Infrastructures and Firms - that interact with and complement each other, within a cooperative, knowledge-sharing culture (e.g., Carayannis, Campbell 2006, 2009; Arnkil et al. 2010; McGregor et al. 2010). Technological Infrastructures consist in R\&D infrastructures. They create networks, partnerships and associations to undertake R\&D, and supply technical products and services (e.g., Etzkowitz, Leydesdorff 2000). As argued by Powell and Grodal (2005), Technological Infrastructures are also crucial in the codification of tacit knowledge in the form of finished inputs, hence enabling the transfer of knowledge through networks. Governments provide the financial support and the regulation system to promote the creation of links between Academia and Firms (science parks, business incubators and other bridge-institutions). Civil Society takes part in the economy by producing, contributing to innovation and demanding higher quality, forever innovative goods and services.

In the new innovation era, competing solely on pure technology has become harder. No single innovative agent has the resources or the competences to act alone. Interdependence of institutions is the result of the emerging innovation economies (OCDE 2009). Firms still maximise their profits, but business culture is changing from "silence is golden" into "we share".

The concept of complementarities (see, e.g., Matsuyama 1995) seems adequate to capture this new innovation era in which all benefit from interaction, cooperation and 
knowledge-sharing. Hence, following Thompson (2008), we assume the existence of complementarities between all entities that contribute in an intermediate level to finalgood production - Academia \& Technological Infrastructures and Firms - which we name the Intermediate Productive Units (IPUs).

Additionally, we capture the costly nature of investment in innovation, by assuming, also as in Thompson (2008), that there are internal costs to investment in both manufacture and innovation.

The Government's role in the introduced model consists in undertaking productive public expenditure on education, health, infrastructures, technological and innovation services and regulations, which increases the productivity of all inputs. We use a Barro's (1990) government expenditure specification.

Civil Society is engaged in production and innovation and also has a demand role, specified on the consumption side of our economy, where citizens (Civil Society) wish to consume innovative goods and services, all aggregated in the form of one final good.

The introduced model carries a second contribution to growth literature in the sense that it is a R\&D-based growth model with public productive expenditure, which, according to Irmen and Kuehnel (2009), is new to the literature on public expenditure and economic growth.

The remainder of the paper is organised as follows. Section 2 describes the model and its main results. Section 3 closes up the paper with some Conclusions.

\section{Specification and results of the model}

Innovation systems constitute environments in which public and private organizations and institutions - governments, universities, research centres, business communities, and funding/financing organizations - collaborate with and compete between each other, generating innovation through interaction of knowledge and information, human resources, financial capital and institutions (Carayannis, Campbell 2006, 2009). The participating elements in the $\mathrm{QH}$ innovation concept are, then, Academia \& Technological Infrastructures (university laboratories and industrial R\&D facilities), Firms, Government and Civil Society.

Innovation processes are not easy to define or manage. According to the Oslo Manual (OECD 2005), the strict definition of innovation is difficult to attain due to the complexity of innovation processes and the different ways in which they can occur according to types of firms and industries. Generally, Academia plays an important role as a source of knowledge and technology. However, the university-industry relationships can be difficult for firms to manage. For instance, new fields of knowledge with high rates of technological progress, like Nano-Bio-TIC, offer promising commercial opportunities, but pose considerable interaction problems between the different entities involved.

As Yawson (2009) writes, before the 2000's the national system of innovation was formed by: (i) a set of institutions, which jointly or individually contributed to the development and diffusion of new technologies; and (ii) the Government which imple- 
mented policies to influence the innovation process. In the 2000's, however, new concepts regarding innovation systems have emerged, such as innovation systems, global networking in value added and innovation, customers and users, systemic thinking and sustainable innovation.

West and Farr (1989: 16), for instance, define innovation as the "... intentional introduction and application within a role, group or organization of ideas, processes, products or procedures, (...) designed to significantly benefit role performance of the group, the organization or the wider society". For Johnson (1992), innovation is a continuous cumulative process involving not only radical and incremental innovation but also the diffusion, absorption and use of innovation. For the OECD (2009), innovation consists in creating value by developing new solutions to specific problems.

We aim to frame this wide definition scope for innovation while also emphasising the idea that the new nature of innovation is essential for smart, inclusive and sustainable economic growth (Europe's 2020 Strategy). Hence the introduced model carries the assumption that the whole society takes part in the innovation process, i.e. we specify a one-sector structure in which innovation is undertaken with the same technology as that of manufacture, by the whole population.

Innovations are materialised in intermediate goods and services (inputs). The final good (aggregate output) is produced using Labour (Civil Society), public expenditure and all the existing inputs. Each input's physical units are produced by Firms and Academia \& Technological Infrastructures.

The model needs to be understood in a circular perspective: All the existing intermediate goods and services are used to produce aggregate output. In turn, aggregate output can be either consumed or invested. Investment consists of innovation expenditure plus physical capital accumulation and is required to innovate and produce more intermediate goods and services, so that the economy grows.

\subsection{Production side - Technology Equation}

The single final good (aggregate output) $Y(t)$ is produced with constant labour (all the economy's citizens, i.e., Civil Society) $L(t)$; public expenditure $G(t)$; and the inputs (intermediate goods and services) $x_{i}(t)$, produced by a number $A(t)$ of intermediate productive units $i,(i=0 \ldots A)$. Each intermediate productive unit is associated with one innovation $i$. Innovations arise as a result of co-creation between Academia \& Technological Infrastructures, Government, Firms and Civil Society, in a one-sector structure framework.

\subsubsection{Government expenditure}

The Government's role in this economy (our innovation system) consists in providing a pure public good - in the form of government expenditure on education, health, infrastructures, technological and innovation services and regulations -, which increases the productivity of all productive factors in the same way. That is, we follow Barro (1990) and assume that productive government expenditure is a flow variable. Thus, in 
Equation 1, the flow of productive government expenditure $G$ is a constant fraction $\tau$ of output $Y$ for all $t$ :

$$
G(t)=\tau Y(t), \quad 0<\tau<1
$$

The government's budget is balanced in all periods. Assuming, for simplicity, zeropublic-debt and zero-consumption-taxes, the government's budget constraint is:

$$
G(t)=T(t)=\tau Y(t)
$$

In Equation 2, $T(t)$ are taxes, that is, total government revenue, at time $t$.

\subsubsection{Intermediate productive units (IPUs)}

We assume that Academy \& Technological Infrastructures and Firms have an identical productive role in this economy. They constitute the intermediate productive units (IPUs) $i,(i=0 \ldots A)$, and produce the (physical) inputs $x_{i}(t)$.

With the goal of capturing the "benefic-for-all" interactions and cooperation between the existing IPUs in innovation systems (e.g., Carayannis 2006, 2009), we assume that IPUs are complementary to each other in the production of aggregate output. Matsuyama (1995), for instance, regards complementarities as a relevant feature of industrialised economies, essential in explaining economic growth, business cycles and underdevelopment.

As in Thompson (2008), building on Evans et al. (1998), we specify that the inputs of the IPUs enter complementarily in the production function for $Y(t)$.

\subsubsection{Final good}

The production function for $Y(t)$ is $Y(t)=L(t)^{1-\alpha-\beta} G(t)^{\beta}\left(\int_{0}^{A(t)} x_{i}(t)^{\gamma} d i\right)^{\phi}$, which, substituting $G(t)$ by its equivalent according to Equation 1, becomes:

$$
Y(t)=\tau^{\frac{\beta}{1-\beta}} L(t)^{\frac{1-\alpha-\beta}{1-\beta}}\left(\int_{0}^{A(t)} x_{i}(t)^{\gamma} d i\right)^{\frac{\phi}{1-\beta}}, \quad \gamma \phi=\alpha, \quad \frac{\phi}{1-\beta}>1 .
$$

In Equation 3, the parameter restriction $\gamma \phi=\alpha$ is imposed to preserve homogeneity of degree one, and assumption $\frac{\phi}{1-\beta}>1$ is made so that the IPUs inputs $x_{i}$ are complementary to one another; i.e., so that an increase in the quantity of one input increases the marginal productivity of the other inputs.

Assuming that it takes one unit of physical capital $K(t)$ to produce one physical unit of any type of IPUs input, $K(t)$ is related to inputs $x_{i}(t)$ by the rule:

$$
K(t)=\int_{0}^{A(t)} x_{i}(t) d i
$$

\subsubsection{Innovation}

An innovation consists in any project useful for concrete problem solving, leading to the production of a technological or non-technological manufactured good or service. We wish to capture the idea that the whole society is involved in the innovation process. 
Florida (2002), for instance, writes that creativity comes from all kinds of people who are the critical resources of modern economies. Karnitis (2006), for example, goes further, highlighting that all social classes must work together in order to achieve common goals, with social inclusion being a prerequisite for growth and development.

Participation of the whole society in the innovation process is possible due to the development of new information and communication technologies (Ginevicius, Korsakiene 2005), allowing individuals to be more active in society.

Following Rivera-Batiz and Romer (1991), we assume the one-sector structure in that innovation is undertaken with the same technology as that of the final good and IPUs inputs. We further assume that innovation $i$ involves a cost equal to $P_{A} i^{\xi}$ units of foregone output, where $P_{A}$ is the fixed cost of one new innovation in units of foregone output, and $i \xi$ represents an additional cost of innovation $i$ in terms of foregone output, meaning a higher innovation cost for higher indexed innovations. Like in Evans et al. (1998), this extra cost is introduced in order to avoid explosive growth.

Accommodating Anagnostopoulou (2008)'s argument, innovation expenditure is specified as part of total capital investment expenses. With zero depreciation for simplicity, total investment in each period $\dot{W}(t)$ is equal to physical capital accumulation $\dot{K}(t)$ plus innovation expenditure $P_{A}(t) \dot{A} A(t)^{\xi}$ :

$$
\dot{W}(t)=\dot{K}(t)+P_{A}(t) \dot{A} A(t)^{\xi} .
$$

Bearing in mind Equation 5, it follows that total capital $W(t)$ is equal to physical capital plus innovation capital:

$$
W(t)=K(t)+P_{A} \frac{A(t)^{\xi+1}}{\xi+1}
$$

It will be later shown that, in a Balanced Growth Path (BGP), $Y$ and $W$ in Equations 3 and 6, respectively, grow at the same rate, which means that we can write aggregate output as a linear function of total capital:

$$
Y(t)=B W(t)
$$

In Equation 7, $B$ is the marginal productivity of total capital, which is constant in a BGP.

\subsubsection{Costly investment}

Agreeing with Benavie et al. (1996) and Romer (1996), our model contemplates investment costs. Following Thompson (2008), we assume that investment in total capital $W(t)$ involves an internal cost, that is, installing $I(t)=\dot{W}(t)$ new units of total capital requires spending an amount given by:

$$
J(t)=I(t)+\frac{1}{2} \theta \frac{I(t)^{2}}{W(t)} .
$$

In Equation 8, $C(I(t), W(t))=\frac{1}{2} \theta \frac{I(t)^{2}}{W(t)}$ represents the Hayashi's (1982) installation cost, with $\theta>0$ standing for the adjustment cost parameter. 
Closing up this one-sector-framework, the economy's budget constraint is given by Equation 9:

$$
I(t)+\frac{1}{2} \theta \frac{I(t)}{W(t)}=Y(t)-G(t)-C(t) .
$$

The equilibrium investment rate maximises the present discounted value of cash flows. The current-value Hamiltonian is:

$$
H(t)=B W(t)-I(t)-\frac{1}{2} \theta \frac{I(t)^{2}}{W(t)}+q(t) I(t) .
$$

In Equation 10, $q(t)$ is the market value of capital and the transversality condition of this optimization problem is $\lim _{t \rightarrow \infty} e^{-r t} q(t) W(t)=0$, with $r$ representing the real interest rate. We solve the model for a particular solution, the BGP, for which growth rates are constant. We will suppress the time argument from now onwards, whenever that causes no confusion. Having in mind that the growth rate of output is $g_{Y}=g_{W}=g=\frac{I}{W}$, the first-order condition, $\frac{\partial H}{\partial I}=0$, is equivalent to:

$$
q=1+\theta g .
$$

Equation 11 says that, in a BGP solution, $q$ is constant.

The co-state equation, $\frac{\partial H}{\partial W}=r q-\dot{q}$, is equivalent to:

$$
\dot{q}=r q-\left(B+\frac{1}{2} \theta g^{2}\right),
$$

which, in a BGP solution, becomes:

$$
q=\frac{B+\frac{1}{2} \theta g^{2}}{r} \text {. }
$$

Equation 12 also implies a constant interest rate $r$.

Let us now build the Technology Equation. Final good producers are price takers in the market for inputs. In equilibrium they equate the rental rate on each input with its marginal productivity. The demand curve faced by each IPU is given by Equation 13:

$$
\frac{\partial Y(t)}{\partial x_{j}(t)}=R_{j}(t)=\frac{\alpha}{1-\beta} \tau^{\frac{\beta}{1-\beta}} L(t)^{\frac{1-\alpha-\beta}{1-\beta}} x_{j}(t)^{\gamma-1}\left(\int_{0}^{A(t)} x_{i}(t)^{\gamma} d i\right)^{\frac{\phi}{1-\beta}-1} .
$$

Turning now to the IPUs' production decisions: Once invented, the physical production of each unit of the input requires one unit of capital. In each period, the monopolistic IPU maximises its profits, taking as given the demand curve for its good:

$$
\max _{x_{j}(t)} \pi_{j}(t)=R_{j}(t) x_{j}(t)-r q x_{j}(t),
$$

which leads to the mark-up rule in Equation 14:

$$
R_{j}=\frac{r q}{\gamma} .
$$

At time $t$, in order to enter the market and produce the Ath input, an IPU must spend upfront an innovation cost given by $P_{A} A(t)^{\xi}$, where, as mentioned earlier, $P_{A}$ is the fixed 
cost of one new innovation, in units of foregone output, and $i^{\xi}$ represents an additional cost of innovation $i$ in terms of foregone output. Hence, the dynamic IPU's zero-profit condition $P_{A} A(t)^{\xi}=\int_{t}^{\infty} e^{-r(s-t)} \pi_{j}(s) d s$ is, assuming no bubbles, equivalent to:

$$
\xi g_{A}=r-\frac{\pi_{j}}{P_{A} A^{\xi}}
$$

The model's symmetry implies that $R_{j}(t)=R(t), x_{j}(t)=x(t)$ and $\pi_{j}(t)=\pi(t)$. Hence $R(t)$ is rewritten as:

$$
R=\Omega_{R} A^{\frac{\phi-1+\beta}{1-\beta}} x^{\frac{\alpha-1+\beta}{1-\beta}} .
$$

In Equation 16, $\Omega_{R}=\frac{\alpha}{1-\beta} \tau^{\frac{\beta}{1-\beta}} L^{\frac{1-\alpha-\beta}{1-\beta}}$ is a constant. Then, profits $\pi(t)=(1-\gamma) R(t) x(t)$ are given by Equation 17:

$$
\pi=\Omega_{\pi} A^{\frac{\phi-1+\beta}{1-\beta}} x^{\frac{\alpha}{1-\beta}}
$$

with $\Omega_{\pi}=(1-\gamma) \Omega_{R}$. And $x$ is equal to:

$$
x=A^{\xi}\left(\frac{\Omega_{R}}{R}\right)^{\frac{1-\beta}{(1-\beta)-\alpha}} .
$$

In Equation 18, we impose the parameter restriction $\xi=\frac{\phi-(1-\beta)}{(1-\beta)-\alpha}$, so that we can
obtain a BGP solution (see Evans et al. 1998). In a balanced growth path, the interest rate and the shadow-value of capital are constant and hence so is $R$. It then follows, from Equation 16, that we must have $\left(\frac{\phi-1+\beta}{1-\beta}\right) g_{A}=-\left(\frac{\alpha-1+\beta}{1-\beta}\right) g_{X}$, that is: $g_{X}=\xi g_{A}, \quad \xi=\frac{\phi-(1-\beta)}{(1-\beta)-\alpha}$.

Symmetry also implies that Equation 4 simplifies to $K=A x$, meaning that $g_{K}=(1+\xi) g_{A}$. Likewise, the production function can now be written as Equation 19:

$$
Y=\tau^{\frac{\beta}{1-\beta}} \frac{1-\alpha-\beta}{L^{1-\beta}} A^{\frac{\phi}{1-\beta}} X^{\frac{\alpha}{1-\beta}},
$$
whose time-differentiation gives $g_{Y}=\left(\frac{\phi+\alpha \xi}{1-\beta}\right) g_{A}=(1+\xi) g_{A}$, allowing us to change
Equation 15 into:

$$
g_{Y}=\frac{1+\xi}{\xi}\left(r-\frac{\Omega_{Y}}{R^{\frac{\alpha}{(1-\beta)-\alpha}}}\right), \quad \Omega_{Y}=\frac{(1-\gamma)}{P_{A}} \Omega_{R}^{\frac{1-\beta}{(1-\beta)-\alpha}} .
$$

Equation 20 is our Technology Equation. It unites the equilibrium BGP pairs of interest rate and economic growth rate $(r, g)$ on the production side of this economy.

\subsection{Consumption side - the Euler Equation}

Civil Society is composed, in this model, by all citizens of the economy, assumed to be infinitely lived, homogeneous, well informed and cultivated. Civil Society wishes 
to consume innovative goods and services, all aggregated in the form of final good $Y$ whose production requires innovation.

Analytically, we can simply adopt the standard specification for intertemporal consumption, as it enables us to convey our interpretation of Civil Society's demand role. Hence, citizens solve an intertemporal optimization problem, that is, they maximise the discounted value of their representative utility (Equation 21), subject to a budget constraint (Equation 22):

$$
\begin{gathered}
\max _{C(t)} \int_{0}^{\infty} e^{-\rho t} \frac{C(t)^{1-\sigma}}{1-\sigma} d t, \\
\text { s.t. } \quad \dot{E}(t)=r E(t)+w(t)-C(t)-T(t),
\end{gathered}
$$

where variable $C$ is consumption of $Y$ in period $t, \rho$ is the rate of time preference, and $\frac{1}{\sigma}$ is the elasticity of substitution between consumption at two periods in time. Variable $E$ stands for total assets, $r$ is the interest rate, $w$ is the wage rate, and it is assumed that each inhabitant provides one unit of labour per unit of time. The transversality condition is $\lim _{t \rightarrow \infty} \mu(t) E(t)=0$, where $\mu(t)$ is the shadow price of assets.

The resulting Civil Society's consumption decisions (in terms of long run consumption growth) are given by the familiar Euler Equation 23:

$$
g_{C}=\frac{\dot{C}}{C}=\frac{1}{\sigma}(r-\rho) \text {. }
$$

\subsection{General equilibrium}

\subsubsection{Analytical solution}

Time-differentiation of the investment Equation $5, \frac{\dot{W}}{W}=\frac{\dot{K}}{K} \frac{K}{W}+\frac{\dot{A}}{A} \frac{A^{1+\xi}}{W} P_{A}$, tells us that $W$ grows at the same rate as $Y$, that is $g_{W}=(1+\xi) g_{A}$.

Then, the economy's budget constraint Equation 9 tells us that a constant growth rate of $W$ implies that consumption grows at the same rate as output. In fact, $\dot{W}=Y-G-C-\frac{1}{2} \theta \frac{I(t)^{2}}{W(t)}$, is equivalent to:

$$
g_{W}=\frac{Y}{W}-\frac{G}{W}-\frac{C}{W}-\frac{1}{2} \theta g^{2} .
$$

According to Equation 24, a constant $g_{W}$ requires that $\left(\frac{\dot{Y}}{W}\right)=\left(\frac{\dot{G}}{W}\right)+\left(\frac{\dot{C}}{W}\right)$. As $G$ and $W$ grow at the same rate as $Y$, then $C$ must also grow at the same rate as $Y$.

Summing up, with labour constant, the per-capita economic growth rate is given by $g_{C}=g_{Y}=g_{K}=g_{W}=g=(1+\xi) g_{A}$.

Hence, the general equilibrium solution is obtained by solving the system of the two Equations 20 and 23, in two unknowns, $r$ and $g$. Recalling Equation 11, the system to be solved is: 


$$
\left\{\begin{array}{c}
g=\frac{1}{\sigma}(r-\rho) \\
g=\frac{1+\xi}{\xi}\left[r-\frac{\Omega}{(r+r \theta g)^{\frac{\alpha}{(1-\beta)-\alpha}}}\right], \quad r>g>0 .
\end{array}\right.
$$

In Equation 25, $\Omega=\gamma^{\frac{\alpha}{(1-\beta)-\alpha}} \frac{(1-\gamma)}{P_{A}} \Omega_{R}^{\frac{1-\beta}{(1-\beta)-\alpha}}$, and $\Omega_{R}=\frac{\alpha}{1-\beta} \tau^{\frac{\beta}{1-\beta}} L^{\frac{1-\alpha-\beta}{1-\beta}}$.

We impose restriction $r>g>0$ so that (i) present values will be finite; and (ii) our solution(s) have positive interest and growth rates.

The Euler Equation 23 is linear and positively sloped in the space $(r, g)$. The Technology Equation 20 is nonlinear, as shown in the Appendix. The model delivers, however, a unique solution.

Proposition 1. The $Q H$ innovation model has a unique solution for $\sigma>1$ and

$$
\Omega^{\frac{1-\alpha-\beta}{1-\beta}}>\rho \text {. }
$$

Proof. Defining two new variables and rewriting our system, we can show that the proposed model has a unique solution. Our new variables are:

$$
Y=\theta g ; \quad Z=r(1+\theta g),
$$

which allows us to rewrite the system as:

$$
\left\{\begin{array}{c}
Z=\frac{\sigma}{\theta}(Y+1)(Y+\eta) \\
Z^{\omega}=\frac{\lambda}{Y+\mu}
\end{array} .\right.
$$

In Equation 26, $\omega=\frac{\alpha}{(1-\beta)-\alpha}, \quad \lambda=\frac{\theta \Omega}{\sigma-\frac{\xi}{1+\xi}}, \quad \mu=\frac{\rho \theta}{\sigma-\frac{\xi}{1+\xi}}, \quad \eta=\frac{\rho \theta}{\sigma}$.

Our restrictions become $Y>0, Z>\frac{1}{\theta} Y(Y+1)$.

To ensure that $r>g$, we impose $\sigma>1$ so that the Euler Equation 23 lies above the $45^{\circ}$ line. This implies that $\lambda, \mu$ and $\eta$ are all positive. Hence, the first equation of the rewritten system defines a strictly decreasing curve $Y \mapsto Z(Y)$ from $Z(0)=\left(\frac{\Omega}{\rho}\right)^{\frac{1}{\omega}}$ to $Z(\infty)=0$, while the second equation defines a strictly increasing curve $Y \mapsto Z(Y)$ from $Z(0)=\rho$ to $Z(\infty)=\infty$. Thus, the system has a unique solution in the region $Y>0$ iff $\Omega>\rho^{\omega+1}$ (which is equivalent to $\Omega^{\frac{1-\alpha-\beta}{1-\beta}}>\rho$ ). The second restriction is also met because $Z=\frac{\sigma}{\theta}(Y+1)(Y+\eta)>\frac{1}{\theta} Y(Y+1)$. 


\subsubsection{Numerical solutions}

Given the nonlinearity of the Technology Equation, we resort to solving the system through a numerical exercise. For the numerical determination of our unique general equilibrium solution, the invariant parameter values considered are:

$\sigma=2 ; \quad \rho=0.02 ; \quad \alpha=0.4 ; \quad \beta=0.3 ; \gamma=0.1 ; \quad \phi=4 ; \xi=11 ; \quad L=1 ; \tau=0.15$,

where the values for $\alpha, \gamma$ and consequently $\phi=\frac{\alpha}{\gamma}$ are the same as those used by Evans et al. (1998) in their numerical example. Consequently $\xi=\frac{\phi-(1-\beta)}{(1-\beta)-\alpha}=11$. The values for the preference parameters $\sigma$ and $\rho$ are in agreement with those found in empirical studies such as Barro and Sala-i-Martin (1995). The value for parameter $\tau$ is in agreement with Irmen and Kuehnel (2009). Population is often chosen to have unity value, so as not to give relevance to the scale-effects prediction that growth depends on the size of the economy, present in many growth models.

We then obtain several possible general equilibrium solutions for different values of parameters $\theta$ and $P_{A}$. The chosen values for $\theta$ and $P_{A}$ are in line with Whited (1992) and Connolly and Valderrama (2005), respectively (Table 1).

Table 1. General equilibrium solutions

\begin{tabular}{cccc}
\hline & $P_{A}=1$ & $P_{A}=6$ & $P_{A}=15$ \\
\hline$\theta=1.5$ & $g=0.0395$ & $g=0.0180$ & $g=0.0117$ \\
\cline { 2 - 4 } & $r=0.0811$ & $r=0.0379$ & $r=0.0254$ \\
\hline$\theta=2$ & $g=0.0391$ & $g=0.0179$ & $g=0.0117$ \\
\cline { 2 - 4 } & $r=0.0802$ & $r=0.0377$ & $r=0.0255$ \\
\hline$\theta=3$ & $g=0.0383$ & $g=0.0177$ & $g=0.0116$ \\
& $r=0.0787$ & $r=0.0374$ & $r=0.0252$ \\
\hline
\end{tabular}

For expositional purposes, selecting the combination $\theta=1.5$ and $P_{A}=6$, the system in Equation 25 is:

$$
\left\{\begin{array}{c}
g=0.5 r-0.01 \\
g=\left(\frac{12}{11}\right)\left[r-\frac{0.000283}{(r+1.5 r g)^{\frac{4}{3}}}\right] .
\end{array}\right.
$$

Figure 1, with $r$ on the horizontal axis and $g$ on the vertical axis, shows the BGP general equilibrium of this economy for the chosen parameters values. We can add that higher values of $\theta$ and $P_{A}$ (for instance, $\theta=50$ and $P_{A}=100$ ) do not alter significantly the configuration of the model. 


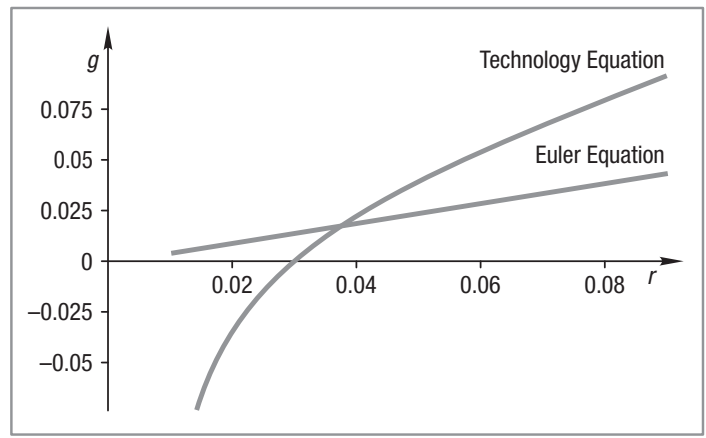

Fig. 1. BGP general equilibrium solution

\subsubsection{Additional results}

Corollary 1. Everything else constant, an increase in the public investment parameter, $\tau$, leads to an increase in the equilibrium growth rate.

Proof. Looking at the rewritten model (26):

$$
\left\{\begin{array}{l}
Z=\frac{\sigma}{\theta}(Y+1)(Y+\eta) \\
Z^{\omega}=\frac{\lambda}{Y+\mu}
\end{array}\right.
$$

naming our curves (A) and (B), curve (A) is positively sloped and curve (B) is negatively sloped in the space $(Z, Y)$. An increase in $\tau$ implies an increase in $\Omega$, meaning that curve (B) shifts to the right. The new equilibrium has higher values for $Z$ and $Y$, as illustrated in Figure 2. Given that $g=\frac{Y}{\theta}$, this implies a higher value for the growth rate $(d r=0)$.

Corollary 2. Everything else constant, an increase in the complementarities parameter, $\frac{\phi}{1-\beta}$, leads to an increase in the equilibrium growth rate.

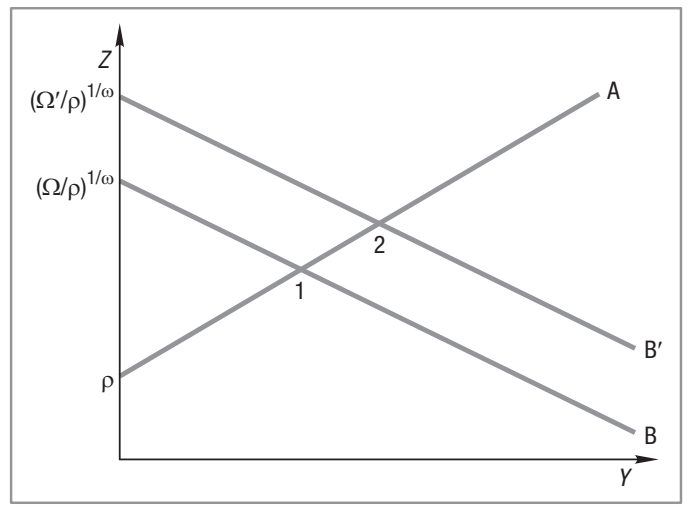

Fig. 2. Comparative statics 
Proof. As in Corollary 1, an increase in $\frac{\phi}{1-\beta}$ implies an increase in $\alpha$, hence an increase in $\Omega$, meaning that curve (B) shifts to the right. The new equilibrium has higher values for $Z$ and $Y$, as illustrated in Figure 2. Given that $g=\frac{Y}{\theta}$, this implies a higher value for the growth rate $(d r=0)$.

\section{Conclusions}

We have developed a R\&D-based growth model with productive public expenditure in order to provide the $\mathrm{QH}$ innovation concept with a first analytical theoretical framework. Within the introduced model, we analyse questions concerning productive public expenditure, the importance to economic growth of complementarities between the different productive units in innovation economies, the relevance of considering the costly nature of investment, and policies to achieve higher economic growth.

As Carayannis and Campbell (2009) refer, QH encompasses structures and processes of the gloCal Knowledge Economy and Society. Innovation systems generate a democracy of knowledge, whose creation is transdisciplinary, non-linear, hybrid and shared. Yawson (2009), for example, writes that advances in biotechnology, ICT and nanotechnology have stimulated innovation and convergence, but at the same time, have revealed the importance of adequate regulations, and have introduced a need for society awareness. Civil Society has thus become an essential helix of innovation systems. The developed QH model considers the innovation economy with four helices: Academia \& Technological Infrastructures (university laboratories and industrial R\&D facilities), Firms, Government and Civil Society, all equally important for smart, inclusive and sustainable economic growth.

The emerging new nature of innovation carries the implication that no single innovative agent has the resources or the competences to act alone. Interdependence of institutions is, indeed, the distinguishing feature of innovation economies. Specifying the beneficial interactions and cooperation between productive units through the presence of complementarities between all the intermediate productive units, the introduced model conveys analytically the result that an increase in complementarities in the innovation economy does increase economic growth.

Yawson (2009) also argues that the QH innovation theory can give orientation in regard of economic policy. Recognizing that innovation by creative citizens determines the success of a country's innovation strategy, innovation systems start with a national innovation goal, which is interpreted through the four helices' perspectives in an integrated form. In the $\mathrm{QH}$ innovation model here proposed, Government provides a pure public good, in the form of productive expenditure on education, health, infrastructure, technological and innovation services and regulations, which increases the productivity of all inputs. The model illustrates analytically that an increase in productive public expenditure does increase the economic growth rate of $\mathrm{QH}$ economies. 
Having framed analytically the new nature of innovation and its impact on economic growth, the next step is to capture this economic dynamics empirically. As Godin (2011) discusses, to measure a country's innovation performance and its impact on the country's economic performance constitutes a true challenge.

\section{References}

Anagnostopoulou, S. C. 2008. R\&D expenses and firm valuation: a literature review, International Journal of Accounting and Information Management 16(1): 5-24.

http://dx.doi.org/10.1108/18347640810887735

Arnkil, R.; Jarvensivu, A.; Koski, P.; Piirainen, T. 2010. Exploring the Quadruple Helix. Work Research Center, University of Tampere.

Barro, R. J. 1990. The stock market and investment, Review of Financial Studies 3(1): 115-131. http://dx.doi.org/10.1093/rfs/3.1.115

Barro, R. J.; Sala-i-Martin, X. 2004. Economic Growth. $2^{\text {nd }}$ ed. McGraw-Hill.

Barroso, J. M. 2010. Europe 2020: A European Strategy for smart, sustainable and inclusive growth, European Commission, COM (3.3.2010).

Benavie, A.; Grinols, E.; Turnovsky, S. J. 1996. Adjustment costs and investment in a stochastic endogenous growth model, Journal of Monetary Economics 38: 77-100.

http://dx.doi.org/10.1016/0304-3932(96)01272-X

Carayannis, E. G.; Campbell, D. F. 2006. Introduction and Chapiters summaries, in Elias, G. C.; Campbell, D. F. J. (Eds.). Knowledge Creation, Diffusion and Use in Innovation Networks and Knowledge Clusters. A Comparative System Approach Accross the United States, Europe and Asia. Praeger, westport, Connecticut, ix-xxvi.

Carayannis, E. G.; Campbell, D. F. 2009. "Mode 3" and "Quadruple Helix": towards a $21^{\text {st }}$ century fractal innovation ecosystem, International Journal of Technology Management 46(3/4): 201-234. http://dx.doi.org/10.1504/IJTM.2009.023374

Chesbrough, H. 2003. Open Innovation: the New Imperative for Creating and Profiting from Technology. Harvard Business School Press: Boston, MA.

Connolly, M.; Valderrama, D. 2005. North-South Technological Diffusion: a New Case for Dynamic Gains from Trade. Duke University WP. Available from Internet:

http://econ.duke.edu/ connolly/Working\%20Papers/North_South_Tech_Diffusion.pdf

Eriksson, M.; Niitamo, V.-P.; Kulkki, S.; Hribernik, K. A. 2006. Living labs as a multi-contextual R\&D methodology, in The 12th International Conference on Concurrent Enterprising: Innovative Products and Services Through Collaborative Networks, ICE 2006. Milan, Italy, June 26-28, 2006.

Etzkowitz, H.; Klofsten, M. 2005. The innovating region: toward a theory of knowledge-based regional development, $R \& D$ Management 35(3): 243-255.

http://dx.doi.org/10.1111/j.1467-9310.2005.00387.x

Etzkowitz, H.; Leydesdorff, L. 2000. The dynamics of innovation: from national systems and "Mode 2" to a triple Helix of University-Industry-Government relations, Research Policy 29(22): 109-123. http://dx.doi.org/10.1016/S0048-7333(99)00055-4

Evans, G.; Honkapohja, S.; Romer, P. 1998. Growth cycles, American Economic Review 88(3): 495-515.

Florida, R. 2002. The Rise of Creative Class: and How Its Transforming Work Leisure Community, and Everyday Life: Basic Books. Cambridge MA. 
Gibbons M.; Limoges, C.; Nowothy, H.; Schwartzman, S.; Scott, P.; Trow, M. 1994. The New Production of Knowledge, the Dynamics of Science and Research in Contemporary Societies. Sage London.

Ginevicius, R.; Korsakiene, R. 2005. The knowledge-based economy in Lithuania: an analysis of tendencies, Journal of Business Economics and Management 6(4): 231-239.

Godin, B. 2011. Taking statistics (more) seriously: the measurement of science, technology and innovation and its future, in Montreal: Centre - Urbanisation Culture Société de L'Institut National de la Recherche Scientifique, 35.

Hayashi, F. 1982. Tobin's marginal q and average q: a neoclassical interpretation, Econometrica 50: 213-224. http://dx.doi.org/10.2307/1912538

Irmen, A.; Kuehnel, J. 2009. Productive government expenditure and economic growth, Journal of Economic Surveys 23(4): 692-733. http://dx.doi.org/10.1111/j.1467-6419.2009.00576.x

Johnson, B. 1992. Institutional learning, in Lundvall, B. (Ed.). National Systems of Innovation: Towards a Theory of Innovation and Interactive Learning. London, Pinter.

Karnitis, E. 2006. A knowledged-based human-centred growth model for Latvia, Journal of Business Economics and Management 7(3): 95-101.

Khan, M. R.; Al-Ansari, M. 2005. Sustainable Innovation as a Corporate Strategy. Available from Internet: http://www.triz-journal.com/archives/2005/01/02.pdf

Liljemark, T. 2004. Innovation Policy in Canada. Strategy and Realities. Swedish Institute for Growth Policy Studies.

MacGregor, S. P.; Marques-Gou, P.; Simon-Villar, A. 2010. Gauging readiness for the quadruple helix: a study of 16 European organizations, Journal of the Knowledge Economy 1(3): 173-190. http://dx.doi.org/10.1007/s13132-010-0012-9

Matsuyama, K. 1995. Complementarities and cumulative processes in models of monopolistic competition, Journal of Economic Literature 33: 701-729.

OECD 2005. Oslo Manual. Paris: OECD.

OECD 2009. New Nature of Innovation. Available from Internet: http://www.newnatureofinnovation.org/full_report.pdf

Powell, W. W.; Grodal, S. 2005. Networks of innovators, in Fagerberg, J.; Mowery, D.; Nelson, R. R. (Eds.). The Oxford Handbook of Innovation. Oxford University Press.

Rivera-Batiz, L.; Romer, P. 1991. Economic integration and endogenous growth, Quarterly Journal of Economics 106: 531-555. http://dx.doi.org/10.2307/2937946

Romer, D. 1996. Advanced Macroeconomics. Mc-Graw-Hill Companies, Inc.

Thompson, M. 2008. Complementarities and costly investment in a growth model, Journal of Economics 94(3): 231-240. http://dx.doi.org/10.1007/s00712-008-0007-1

Von Hippel, E. 2005. Democratizing Innovation. The MIT Press. Cambridge, Massachusetts.

West, M.; Farr, J. 1989. Innovation at work: psychological perspectives, Social Behaviour 4: $15-30$.

Whited, T. M. 1992. Debt, liquidity constraints, and corporate investment: evidence from panel data, Journal of Finance 47(4): 1425-1460.

Yawson, R. M. 2009. The ecological system of innovation: a new architectural framework for a functional evidence-based platform for science and innovation policy, in The Future of Innovation Proceedings of the XXIV ISPIM 2009 Conference. Vienna, Austria, June. 


\section{APPENDIX}

In order to analyse the shape of the Technology Equation (20), and as it is impossible to isolate $r$ on one side of the equation, we rewrite it as $F(r, g)=0$ and apply the implicit function theorem, so as to obtain, in the neighbourhood of an interior point of the function, the derivative $\frac{d r}{d g}$ :

$$
F(r, g)=\xi g-(1+\xi) r+(1+\xi) \Omega_{Y} r^{\frac{-\alpha}{1-\beta-\alpha}}(1+\theta g)^{\frac{-\alpha}{1-\beta-\alpha}}=0,
$$

which leads to:

$$
\frac{d r}{d g}=-\frac{\frac{d F(r, g)}{d g}}{\frac{d F(r, g)}{d r}}=\frac{\xi-\left(\frac{\alpha}{1-\beta-\alpha}\right) \theta(1+\xi) \Omega_{Y} r^{\frac{-\alpha}{1-\beta-\alpha}}(1+\theta g)^{\frac{\beta-1}{1-\beta-\alpha}}}{(1+\xi)+\left(\frac{\alpha}{1-\beta-\alpha}\right)(1+\xi) \Omega_{Y} r^{\frac{\beta-1}{1-\alpha}}(1+\theta g)^{\frac{-\alpha}{1-\beta-\alpha}}} .
$$

Hence, our nonlinear Technology Equation is positively sloped when:

and negatively sloped otherwise.

$$
r^{\frac{-\alpha}{1-\beta-\alpha}}(1+\theta g)^{\frac{\beta-1}{1-\beta-\alpha}}<\frac{\xi}{\left(\frac{\alpha}{1-\beta-\alpha}\right) \theta(1+\xi) \Omega_{Y}},
$$

Oscar AFONSO has obtained MA and PhD degrees in Economics from the University of Porto. He is Assistant Professor at Faculty of Economics, University of Porto, and researcher at CEFUP (Center in Economics and Finance) and OBEGEF (Observatory in Economics and Management of Fraud). He has published a book, book chapters and articles in Acta Oeconomica, Advances in Management and Applied Economics, Applied Economics, Applied Economics Letters, Economic Modelling, Economics Letters, Ekonomiaz, Economics Research International, European Research Studies Journal, Intereconomics, International Economic Journal, International Trade Journal, Japanese Economic Review, Journal of International Trade and Economic Development, Manchester School, Open Business Journal and Review of World Economics. He has been teaching Computational Economics (Doctoral Program in Economics), Economic growth (Master and Doctoral Program in Economics), Macroeconomics (Undergraduate Economics) and International trade (Undergraduate Economics).

Sara MONTEIRO has obtained degree in Economics from the University of Coimbra and MA degree from the University of Nice with empirical work where it has been tested the integrated model IMF-WB using Mozambique source data. She's finishing a PhD Thesis in subject of Human Capital, Technological Diffusion and Economic Growth at CEMAFI at university of Nice, France. She has successfully achieved a PhD Academic Program in "Innovation, Knowledge and Governance" subject in Coimbra University. She has successfully finished post-grade in Entrepreneurial and Enterprise Creation in Indeg-Iscte Business School, Lisbon. She's member of Eurofact IEE-European Think Thank where she produces scientific and political documents about Europe and leads the Innovation and Technological Working Group. She's also corporate member of Nanotechnology Atlantic Center International Organization (NanoAC) managed by University of Aveiro. She has close participation in the following business networks: GASD to promote the European Maritime Cluster, Living Labs, Fab Labs (MIT), Incubator Forum, UTEN-Austin University, EuropaBio, EBN-European Business Network, Fraunhofer IGC. She's Executive Manager at P-Bio-Portugal's Biotechnology industry. She's also Executive Manager at Instituto Pedro Nunes-TecBIS from the University of Coimbra where she's in charge by Business Internationalization. 
Maria THOMPSON has obtained MSc and PhD degrees in Economics from the University of Warwick. She is Assistant Professor at the School of Economics and Management, University of Minho, and researcher at NIPE (Economic Policies Research Unit). She has published articles in Journal of Economics, Economic Modelling, Journal of International Trade and Economic Development, Open Journal of Economics. She teaches Economic growth (Master and Doctoral Program in Economics), Macroeconomics (Undergraduate Degree in Economics) and Macroeconomics (Master Program in Markets and Economic Policy and Master Program in Monetary and Financial Economics). The main research topic is economic growth. 